\title{
Myofascial pain in patients waitlisted for total knee arthroplasty
}

\author{
Richard Henry MD¹, Catherine M Cahill PhD ${ }^{1,2,3}$, Gavin Wood MD4, Jennifer Hroch¹, \\ Rosemary Wilson RN(EC) PhD ${ }^{1,5}$, Tracy Cupido DO ${ }^{1}$, Elizabeth VanDenKerkhof RN DrPH ${ }^{1,5}$
}

\begin{abstract}
R Henry, CM Cahill, G Wood, et al. Myofascial pain in patients waitlisted for total knee arthroplasty. Pain Res Manage 2012;17(5):321-327.
\end{abstract}

BACKGROUND: Knee pain is one of the major sources of pain and disability in developed countries, particularly in aging populations, and is the primary indication for total knee arthroplasty (TKA) in patients with osteoarthritis (OA).

OBJECTIVES: To determine the presence of myofascial pain in $\mathrm{OA}$ patients waitlisted for TKA and to determine whether their knee pain may be alleviated by trigger point injections.

METHODS: Following ethics approval, 25 participants were recruited from the wait list for elective unilateral primary TKA at the study centre. After providing informed consent, all participants were examined for the presence of active trigger points in the muscles surrounding the knee and received trigger point injections of bupivacaine. Assessments and trigger point injections were implemented on the first visit and at subsequent visits on weeks 1, 2, 4 and 8. Outcome measures included the Timed Up and Go test, Brief Pain Inventory, Centre for Epidemiologic Studies Depression Scale, State-Trait Anxiety Inventory and Short-Form McGill Pain Questionnaire.

RESULTS: Myofascial trigger points were identified in all participants. Trigger point injections significantly reduced pain intensity and pain interference, and improved mobility. All participants had trigger points identified in medial muscles, most commonly in the head of the gastrocnemius muscle. An acute reduction in pain and improved functionality was observed immediately following intervention, and persisted over the eightweek course of the investigation.

CONCLUSION: All patients had trigger points in the vastus and gastrocnemius muscles, and $92 \%$ of patients experienced significant pain relief with trigger point injections at the first visit, indicating that a significant proportion of the OA knee pain was myofascial in origin. Further investigation is warranted to determine the prevalence of myofascial pain and whether treatment delays or prevents TKA.

Key Words: Myofascial pain; Osteoarthritis; Pain assessment; Total knee replacement; Trigger point

$\mathrm{O}$ steoarthritis (OA) is the most common form of arthritis, with symptomatic disease (pain) of the knee affecting $6 \%$ of all people older than 30 years of age, increasing to approximately $10 \%$ at 65 years of age, with further increases thereafter $(1,2)$. Knee pain is one of the major sources of pain and disability in developed countries, particularly in aging populations (3), and is the primary indication (94\%) for total knee arthroplasty (TKA) in patients with OA (4). TKA was first performed more than 50 years ago and is increasingly used to treat patients with painful, deformed and unstable knees secondary to degenerative or inflammatory conditions. Although TKA represents the most significant advancement in the treatment of $\mathrm{OA}$ in the past century, it has limited durability in patients with life expectancies exceeding 20 years and in those who wish to participate in highdemand activities (5). The Canadian Joint Replacement Registry

\section{La douleur myoaponévrotique chez les patients en attente d'une arthroplastie totale du genou}

HISTORIQUE : La douleur au genou est l'une des principales sources de douleur et d'invalidité dans les pays industrialisés, notamment dans les populations vieillissantes, et c'est une indication primaire d'arthroplastie totale du genou (ATG) chez les patients atteints d'arthrose.

OBJECTIFS : Déterminer la présence de douleur myoaponévrotique chez des patients souffrant d'arthrose en attente d'une ATG et établir si leur douleur au genou est soulagée par des injections aux points déclencheurs. MÉTHODOLOGIE : Après une approbation éthique, les chercheurs ont recruté 25 participants à partir de la liste d'attente d'ATG primaire unilatérale non urgente du centre à l'étude. Les chercheurs ont obtenu le consentement éclairé de tous les participants et les ont examinés pour déterminer la présence de points déclencheurs actifs dans les muscles entourant le genou, puis y ont administré des injections de bupivacaine. Ils ont procédé aux évaluations et effectué les injections aux points déclencheurs à la première visite et aux visites subséquentes les première, deuxième, quatrième et huitième semaines. Les mesures d'issue incluaient le test pour se lever et marcher, le bref inventaire de la douleur, l'échelle de dépression du Centre for Epidemiologic Studies, l'inventaire des caractéristiques anxieuses et le court questionnaire sur la douleur de McGill.

RÉSULTATS : Les chercheurs ont déterminé les points déclencheurs de la douleur myoaponévrotique chez tous les participants. Les injections aux points déclencheurs réduisaient l'intensité de la douleur et l'interférence de la douleur tout en améliorant la mobilité. Tous les participants avaient des points déclencheurs déterminés dans les muscles médians, le plus souvent à la tête du muscle gastrocnémien. Les chercheurs ont observé une réduction aiguë de la douleur et une amélioration de la fonction immédiatement après l'intervention, lesquelles se sont maintenues pendant les huit semaines de la recherche.

CONCLUSION : D'après les observations primaires, tous les patients avaient des points déclencheurs dans les muscles vastes et gastrocnémiens, et $92 \%$ des patients ont ressenti un important soulagement de la douleur après des injections aux points déclencheurs à la première visite, indiquant qu'une forte proportion de la douleur causée par l'arthrose du genou était d'origine myoaponévrotique. D'autres explorations s'imposent pour déterminer la prévalence de la douleur myoaponévrotique et pour établir si le traitement retarde ou prévient l'ATG.

2009 Annual Report cites a 300\% increase in the overall number of TKAs performed over the past decade, with the most notable increase occurring among individuals 45 to 54 years of age (4).

Knee pain is considered to be a better predictor of disability than radiographic changes in OA, which have been shown to bear no correlation to function $(6,7)$. Interestingly, radiological changes do not correlate with clinical pain $(4,8)$. Considering that $\mathrm{OA}$ is believed to affect joints, ligaments, tendons, bones and the musculoskeletal system, and that joint damage does not predict pain intensity or disability, many patients may be undergoing TKA unnecessarily (9). A recent study demonstrated that arthroscopic surgery, a common treatment for joint pain and stiffness, provided no additional therapeutic value for patients with moderate OA $(10,11)$. The European League Against Rheumatism Standing Committee has found category 3

Departments of ${ }^{1}$ Anesthesiology and Perioperative Medicine; ${ }^{2}$ Biomedical and Molecular Sciences; ${ }^{3}$ Centre for Neuroscience Studies; ${ }^{4}$ Orthopedics;

${ }^{5}$ School of Nursing, Queen's University, Kingston, Ontario

Correspondence: Dr Catherine Cahill, Departments of Anesthesiology and Biomedical and Molecular Sciences, Queen's University, 516 Botterell,

18 Stuart Street, Kingston, Ontario K7L 3N6. Telephone 613-533-6162, fax 613 533-6674, e-mail cahillc@queensu.ca 
evidence for TKA, noting that no studies have been found that compare TKA with nonsurgical treatment (12).

The prevalence of myofascial pain in all patients presenting with chronic pain is very high (ranging from 35\% to 95\%) (13). Diagnosis of myofascial pain is predicated on the patient feeling pain on stretching or contracting the affected muscle and the identification of tender trigger points in those muscles. In the knee, the affected muscles are all four heads of the quadriceps femoris muscle anteriorly and the hamstring muscles posteriorly (14). Injection of trigger points with local anesthetic causes immediate intense pain followed by a rapid diminution or cessation of the pain and tenderness. This provides a potential method to ascertain the proportion of pain attributable to the affected muscles versus the knee joint itself $(15,16)$.

In the present study, we investigated the prevalence and location of myofascial pain in OA patients who have been diagnosed with $\mathrm{OA}$ knee pain severe enough to warrant TKA, and assessed the response to trigger point injection therapy to decrease pain and improve function. Our hypothesis was that myofascial pain contributes to chronic knee pain in patients diagnosed with $\mathrm{OA}$, and our primary objective was to define the relative contribution of myofascial pain to the patient's overall pain and immobility.

\section{METHODS}

\section{Participants}

Following approval from the institutional research ethics board (\#ANAE-150-09), OA patients on the wait list for TKA were recruited into the study. Following signed informed consent, eligible participants were recruited from the wait list for routine, elective, unilateral primary TKA at the study centre. Eligible patients required a diagnosis of OA that was confirmed on $\mathrm{x}$-ray as indicated by loss of joint space, cysts, subchondral sclerosis or the presence of osteophytes. Documentation of diagnosis was provided by the attending orthopedic surgeons on patients for whom conservative management techniques failed. Exclusion criteria were an allergy or known contraindication to local anesthetics and any patient listed for unicompartmental, revision or bilateral knee arthroplasty.

\section{Study design and procedures}

The present nonrandomized, nonblinded prospective cohort study investigated the presence and location of myofascial pain in patients on the wait list for TKA to treat OA causing knee pain at a tertiary level academic centre. The study consisted of five assessments and possible interventions over eight weeks beginning at the first interview and at one-, two-, four- and eight-week follow-up time points. On arrival in the clinic (week 0), potential participants were provided with a detailed verbal and written explanation of the study by the research assistant. Participant rights, confidentiality, and the risks and benefits of participation were reviewed and questions answered by the principal investigator before the consent form was signed and baseline data collection was performed. All participants received an additional copy of the consent/study information form detailing the investigator information, study purpose and outline. At each visit, patients were instructed to complete pain assessment questions before examination by the principal investigator, followed by an assessment of the occurrence of myofascial pain. If myofascial pain was diagnosed in muscles around the knee, injections of local anesthetic $(0.25 \%$ bupivacaine, 25 -gauge, 1.5 inch needle) were made at points of maximum tenderness. Injections were performed until the pain ceased or no further triggers were found. The number and location of trigger points injected, and the volume of local anesthetic at each site, was documented. Additional assessment forms were completed after intervention. No modifications were made to medications taken by the participants during the study period.

\section{Study protocol}

Eligible participants were contacted by telephone to determine interest in participating in the study. All patients who agreed to participate were booked into a special outpatient clinic in the study centre. Once the consent form was signed, demographics, pain assessment, depression and anxiety data were collected using the following questionnaires: the Baseline Demographics Questionnaire; the Brief Pain Inventory (BPI); the Short-Form McGill Pain Questionnaire (SF-MPQ); the Centre for Epidemiologic Studies Depression Scale (CES-D); the State-Trait Anxiety Inventory (STAI); and the 12-item Short Form Health Survey (SF-12). Assessment of the Timed Up and Go test (TUG) was performed before and following intervention at each visit. The TUG is a validated measurement of mobility (25). The test involves standing from a sitting position, walking, turning, stopping and sitting down, which are all important tasks needed for a person to be independently mobile.

On completion of baseline data capture, participants were assessed for myofascial knee pain by the study investigator using manual palpation. Briefly, the incidence of active trigger points was indicated by a taut palpable band in the muscle, point tenderness in the taut band, replication of their knee pain with point compression and exacerbation of point compression-induced pain with muscle contraction (ie, enhanced pain elicited by standing from a sitting position with point compression of the affected muscle). Patients were examined for the presence of myofascial trigger points in various muscles around the knee and in the leg including the quadriceps femoris, gastrocnemius and hamstring muscles. At each visit, all trigger points identified were recorded and injected with bupivacaine. Participants who did not exhibit trigger points at the initial examination or at subsequent visits provided a brief description of their overall knee pain and did not receive trigger point injections.

Participants who had documented trigger points received the study intervention from the principal investigator following their initial assessment. Data were collected before and immediately following the intervention at each of the five time points over the eight-week period. All participants were observed for 20 min following the intervention at each visit. Following the observation period, participants were discharged from the clinic and an appointment time for a return visit was given to the participant. Participants received a reminder telephone call of their booked clinic appointment. At time points 1 and 5 (week 0 and week 8), participants were instructed to complete all outcome measures listed above before and following intervention. For time points 2, 3 and 4, participants were required to compete the BPI, SF-MPQ and TUG before and 20 min following intervention. The study investigator reassessed each participant on each visit and documented trigger points before and 20 min following intervention. Participants were offered the option to continue therapy in the clinic following the end of the study.

\section{Outcomes}

Outcome measures were selected following published recommendations for clinical trials of chronic pain (17). Pain-related interference with activity was defined as the degree to which pain interfered with activity and function. Pain-related interference with general activities, sleep, mood, walking, climbing stairs and relations with others was measured using the BPI (18). Pain quality was assessed using the SF-MPQ (19). Depression was screened by the CES-D. The operational definition of depression for the present study was self-reported low mood affecting enjoyment and function in life. A CES-D score $\geq 16$ indicated a greater number of depressive symptoms and suggested a risk of depression that required treatment $(20,21)$. The STAI was used to measure state and trait anxiety $(22,23)$. The SF-12 was used to capture practical, reliable and valid information about functional health and well-being from the patient's point of view.

Primary end points included severity of pain (BPI pain severity score); confirming the myofascial pain component with an Improved Brief Pain Inventory score $>20 \mathrm{~mm}$ on a $100 \mathrm{~mm}$ scale after intervention; and location of trigger points. The present study also assessed the following characteristics of the study sample: pain quality (SF-MPQ); depression (CES-D); anxiety (STAI-T); mobility (TUG); and health survey $(\mathrm{SF}-12)$. 


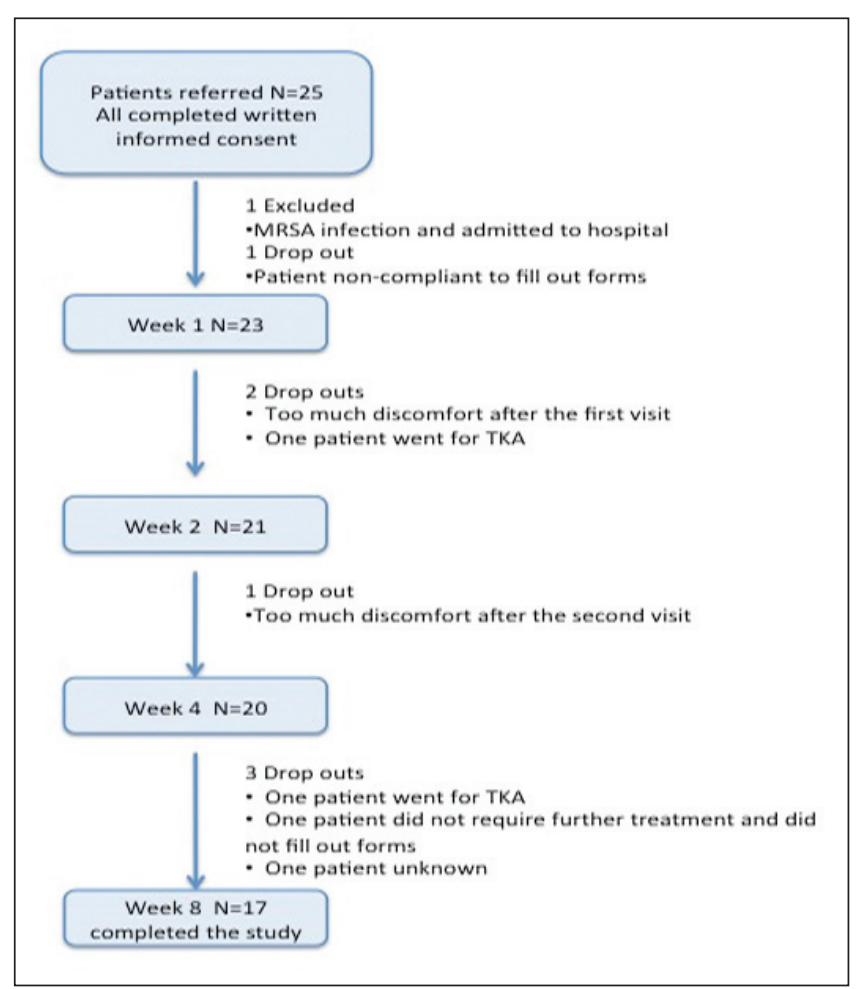

Figure 1) Flow chart of patients throughout the study period (eight weeks). MRSA Methicillin-resistant Staphylococcus aureus; TKA Total knee arthroplasty

\section{Statistics}

The prevalence of myofascial pain was assessed by identifying trigger points in muscles around the knee. The myofascial component of the aggregate pain was confirmed by the relief of pain brought on by the intervention with local anesthetic. The comparison of within-patient average weekly pain intensity and pain interference on week 0 compared with all other time points including immediately after intervention at individual time points was of primary interest. A patient sample size of 25 was targeted to assess study feasibility and assuming a within-patient difference of $20 \mathrm{~mm}$ on a $100 \mathrm{~mm}$ scale, with a standard deviation of $20 \mathrm{~mm}$, and with $80 \%$ power and $5 \%$ significance. This magnitude of change was selected because a two-point reduction on an 11-point numerical rating scale represents a moderate improvement in pain (24). Demographic, psychological and pain data were summarized using frequencies, percentages, means $( \pm$ SD) and medians (with 25th and 75th percentile) as appropriate. KruskalWallis ANOVAs were used to estimate the change in pain over time (pre- and postintervention) and post hoc Dunn's tests were conducted to account for multiple comparisons. The Wilcoxon signed-rank test and paired $t$ test data are expressed as mean $\pm \mathrm{SD}$, or medians with 25 th and 75 th percentile, as appropriate. Secondary measures were calculated in the same way. Data from all participants were included in all analyses. All statistical outcomes are provided in the figure legends and include nonparametric Kruskal-Wallis ANOVAs followed by Dunn's multiple comparison post hoc analysis, the Wilcoxon signed-rank $t$ test test and a paired Student's $t$ test for TUG scores.

\section{RESULTS}

\section{Participants}

In total, 25 participants were interviewed and all were enrolled in the study following signed informed consent to participate. The study sample consisted of 10 men and 15 women, 40 to 70 years of age (Figure 1). On the initial visit, one patient was excluded due to a methicillin-resistant Staphylococcus aureus infection that required
TABLE 1

Demographic and baseline characteristics of participants $(n=24)$

\begin{tabular}{|c|c|}
\hline Characteristic & \\
\hline Age, years, mean \pm SD (range) & $64.2 \pm 7.14(51-81)$ \\
\hline \multicolumn{2}{|l|}{ Sex } \\
\hline Male & $9(37.5)$ \\
\hline Female & $15(62.5)$ \\
\hline \multicolumn{2}{|l|}{ Education } \\
\hline High school without diploma & $9(37.5)$ \\
\hline High school with diploma & $2(8.3)$ \\
\hline Trade or professional certificate & $10(41.7)$ \\
\hline University degree and/or post graduate degrees & $3(12.5)$ \\
\hline \multicolumn{2}{|l|}{ Employment status } \\
\hline Full-time or part-time & $5(20.8)$ \\
\hline Homemaker & $2(8.3)$ \\
\hline Retired & $14(58.3)$ \\
\hline Other & $3(12.5)$ \\
\hline \multicolumn{2}{|l|}{ Visits in the last year because of pain, mean \pm SD (range) } \\
\hline Doctor, specialist, emergency room & $6.08 \pm 6.13(0-24)$ \\
\hline Other health care professional & $2.25 \pm 5.20(0-7)$ \\
\hline \multicolumn{2}{|l|}{ Medications } \\
\hline Opioids & $8(33.3)$ \\
\hline Nonsteroidal anti-inflammatory drugs & $8(33.3)$ \\
\hline Acetaminophen & $10(41.7)$ \\
\hline Other & $2(8.3)$ \\
\hline Time since initial diagnosis, months, mean \pm SD (range) & $70.8 \pm 90.6(0-360)$ \\
\hline
\end{tabular}

Data presented as $n$ (\%) unless otherwise indicated

admission to a primary care facility. The remaining 24 participants had active trigger points in multiple sites, including quadriceps, hamstrings and gastrocnemius muscles, and received intervention via injection of local anesthetic. Thus, every patient contacted and recruited to the study presented with active trigger points and received trigger point injections. At week 1 follow-up, one participant decided not to complete the questionnaires for personal reasons and dropped out, leaving 23 participants. Two additional participants dropped out of the study after week 1: one patient had her scheduled TKA surgery moved forward and elected to take the opportunity and the other indicated that they were in too much discomfort to continue as the result of the trigger point injections. Following the third visit, one additional patient dropped out of the study, again citing that they were in too much discomfort due to the trigger point injections to continue. There were three subsequent dropouts between weeks 4 and 8 , one of whom underwent TKA surgery, one who indicated that they no longer needed treatment and one who did not provide information. Seventeen patients $(71 \%)$ completed the study, $8 \%$ dropped out due to too much discomfort with injections that may be considered as adverse events of the therapeutic intervention, $8 \%$ underwent TKA surgery before study completion and $8 \%$ dropped out for unknown reasons. Demographic and baseline pain characteristics of the participants are summarized in Table 1.

\section{Primary outcome}

In the present study, trigger points in affected leg muscles around the knee were identified and injected until the patient reported that his/her pain at rest had settled or there were no more trigger points identified. Outcome measures were obtained before and 20 min following intervention. All participants presented with active trigger points in muscles around the knee, mostly affecting medial muscles (including the medial head of gastrocnemius muscle [92\%] and the vastus medialis muscle [67\%]), with no participant presenting with knee pain in only lateral muscles (Table 2, Figure 2). Nearly all participants reported a reduction in pain intensity and pain interference immediately 
TABLE 2

Presence of trigger points in vastus and gastrocnemius muscles*

\begin{tabular}{|c|c|c|c|c|c|c|c|c|c|c|c|c|c|c|c|c|c|c|c|c|c|c|c|c|c|}
\hline & \multicolumn{25}{|c|}{ Patient } \\
\hline & 1 & 2 & 3 & 4 & 5 & 6 & 7 & 8 & 9 & 10 & 11 & 12 & 13 & 14 & 15 & 16 & 17 & 19 & 20 & 21 & 22 & 23 & 24 & 25 & $\%$ \\
\hline Trigger points, n & 1 & 6 & 4 & 3 & 6 & 5 & 6 & 4 & 4 & 13 & 6 & 6 & 2 & 13 & 5 & 3 & 2 & 4 & 9 & 2 & 4 & 1 & 1 & 2 & \\
\hline Medial & & & & & & & & & & & & & & & & & & & & & & & & & \\
\hline Vastus muscle & & $\checkmark$ & $\checkmark$ & $\checkmark$ & $\checkmark$ & $\checkmark$ & $\checkmark$ & $\checkmark$ & $\checkmark$ & $\checkmark$ & $\checkmark$ & $\checkmark$ & & $\checkmark$ & & & & $\checkmark$ & $\checkmark$ & & $\checkmark$ & & & $\checkmark$ & 67 \\
\hline Lateral & & & & & & & & & & & & & & & & & & & & & & & & & \\
\hline
\end{tabular}

*62.5\% of participants had trigger points in medial muscles only, $0 \%$ in lateral muscles only, and $37.5 \%$ of participants had pain in both medial and lateral muscles

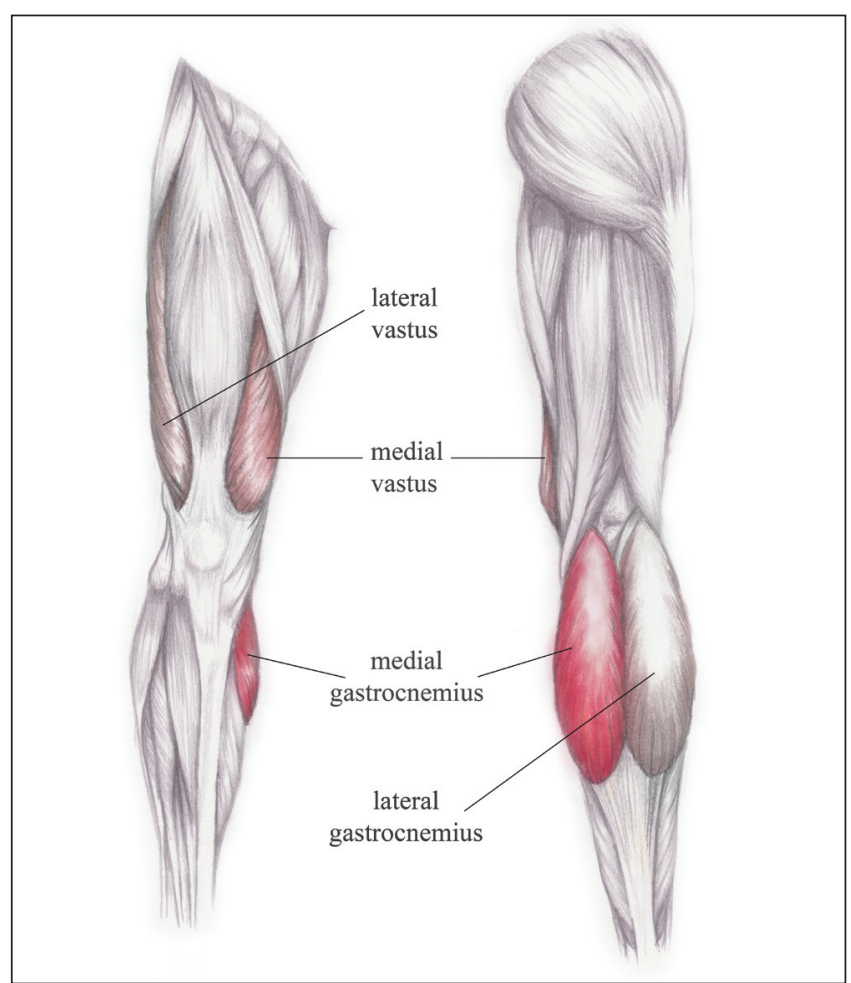

Figure 2) Schematic diagram of the most commonly identified trigger point locations in the present study. Muscles coloured in red presented with the most common active trigger points that accounted for knee pain. The intensity of the colour shading indicates the most common muscle affected, with the deep red colour indicating the muscle with the most prominent active trigger points

following intervention at the initial assessment on week 0 as measured by the BPI (Figure 3). Current ('right now') pain intensity was significantly reduced when assessed $20 \mathrm{~min}$ following trigger point injection compared with preinjection values (Figure $3 \mathrm{~A}, \mathrm{P}<0.001$ ). Further analysis revealed that $92 \%$ of participants $(22 / 24)$ reported a reduction in pain intensity of $20 \mathrm{~mm}$ or more on a $100 \mathrm{~mm}$ scale, whereas $8 \%$ (2/24) reported less than a $20 \mathrm{~mm}$ change following intervention. Similarly, patients experienced an immediate reduction in pain interference (Figure 3B) following the intervention at week 0 , whereby $78 \%$ of participants reported at least a $20 \mathrm{~mm}$ decrease on a $100 \mathrm{~mm}$ scale, with only $13 \%$ reporting less than a $20 \mathrm{~mm}$ change; two patients failed to complete the assessment following intervention (Figure 3).

The pain intensity (preinjection) measured in the clinic was significantly reduced at weeks 4 and 8 compared with the initial time point (week 0) (Figure 4A, K=20.34, $\mathrm{P}<0.001$ ). Pain interference (preinjection) was also significantly reduced after the initial visit (week 0 ) at all time points (Figure 4B, $K=31.86, P<0.0001$ ). Pain intensity (right now) was significantly reduced immediately after intervention at each time point (Figure 4A). A similar analysis of pain

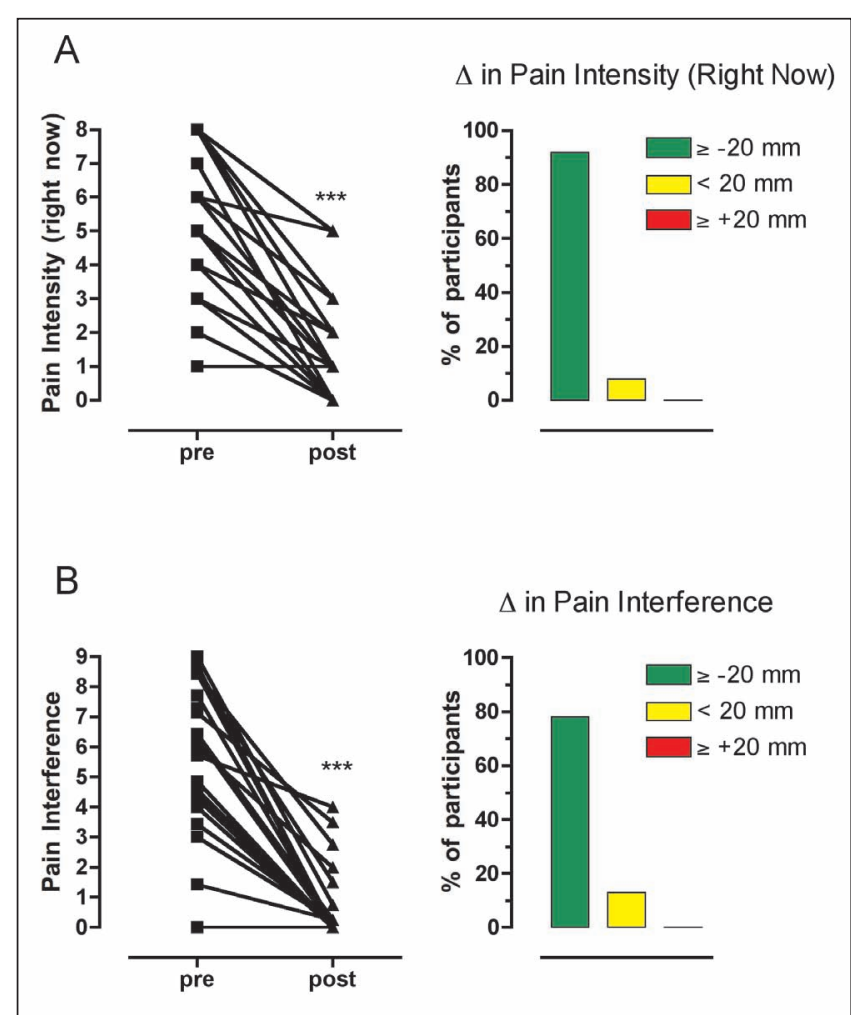

Figure 3) Evidence of myofascial pain in osteoarthritis patients by reductions in pain scores before (pre) and following (post) intervention at the first interview (week 0) as measured by the brief pain inventory questionnaire. A Pain intensity right now was significantly attenuated, with $92 \%$ of participants reporting a reduction of more than $20 \mathrm{~mm}$ on a $100 \mathrm{~mm}$ scale (right column). B Pain interference was significantly attenuated, with $78 \%$ of participants reporting a reduction of more than $20 \mathrm{~mm}$ on a $100 \mathrm{~mm}$ scale. Statistical analysis were performed with a Wilcoxon signed-rank test comparing pre-and post-trigger point injection values. $* * * P<0.001$

interference revealed a significant effect of trigger point intervention at week 8 compared with week 0 (Figure 4B).

\section{Secondary outcomes}

Participants' overall pain intensity $(\mathrm{KW}=21.81, \mathrm{P}=0.002)$, visual analogue scale $(\mathrm{KW}=14.7, \mathrm{P}=0.05)$, sensory pain rating index $(\mathrm{KW}=12.96$, $\mathrm{P}=0.0015)$ and total pain rating index $(\mathrm{KW}=16.9, \mathrm{P}=0.002)$ improved over time, but affective pain rating index did not $(\mathrm{KW}=7.91$, $\mathrm{P}=0.095)$.

Responses to the SF-12 health survey demonstrated higher scores in all categories except social function. Statistically significant effects of intervention were identified for improved physical functioning $(\mathrm{P}=0.0312)$ and vitality $(\mathrm{P}=0.0371)$ comparing the initial assessment with week 8 . There were no effects on anxiety or depression outcomes 


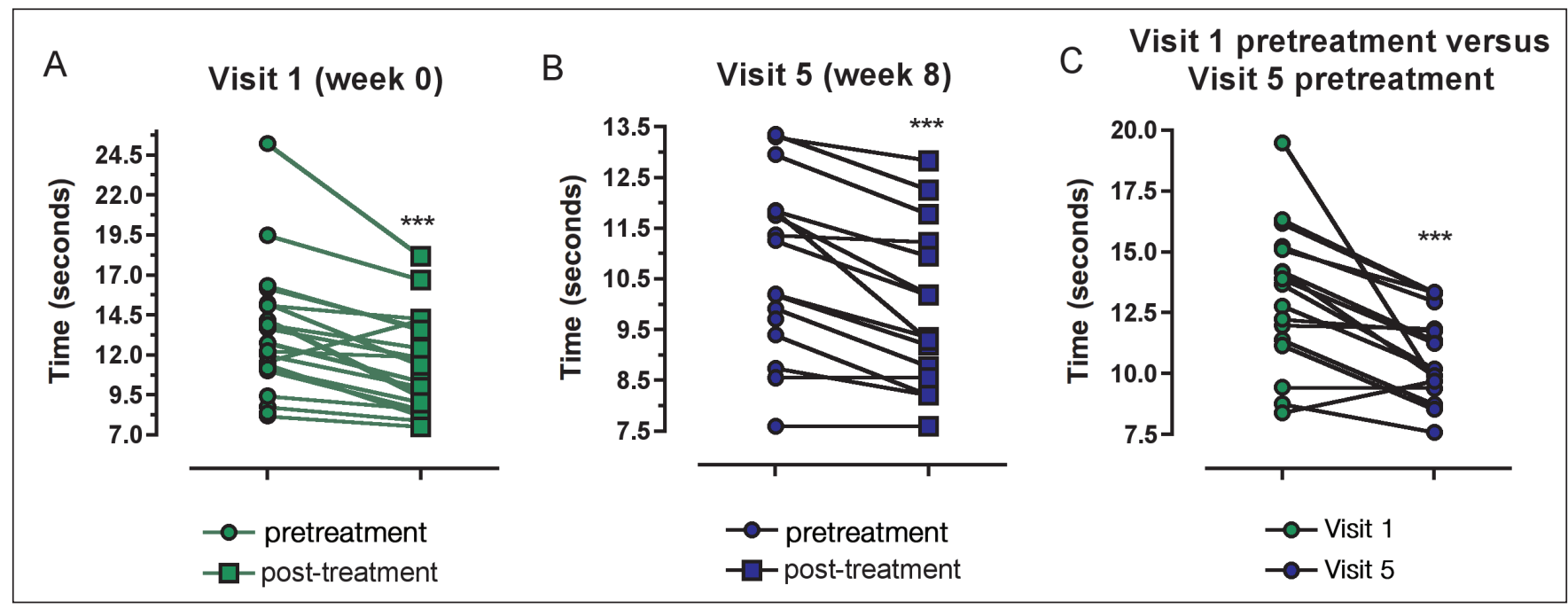

Figure 5) Time to Up and Go (TUG) analysis for osteoarthritis participants before and following intervention (trigger point injections with bupivacaine [0.25\%]) at the initial interview (week 0) and at week 8 are presented. A TUG scores were significantly lower 20 min after intervention on the first visit; $t=5.628, d f=21, * * * P=0.0001$. B TUG scores were significantly different before and following intervention on week $8 ; t=4.871, d f=15, * * * P=0.0002$. C TUG scores were significantly different between before treatment on first visit and before treatment on week $8 ; t=5.354, d f=15, * * * P<0.0001$

at any time point throughout the study compared with the initial visit report. However, these patients scored quite well on these surveys, with a CES-D score of 16.1 and a STAI-T score of 39.3, indicating that participants did not suffer from either disorder.

On the first interview, patients performed the TUG in a mean time of $13.3 \mathrm{~s}$ ( $95 \%$ CI $11.6 \mathrm{~s}$ to $15.0 \mathrm{~s}$ ). This time significantly shortened following intervention to $11.04 \mathrm{~s}$ (95\% CI $11.6 \mathrm{~s}$ to $12.4 \mathrm{~s}$ ) (Figure 5A). The intervention also reduced TUG scores when measured before and following intervention at week 8 with a reduction from a time of $10.7 \mathrm{~s}$ ( $95 \%$ CI 9.82 s to 11.7 s) to 9.70 s (95\% CI 8.73 s to 10.6 s) (Figure 5B). Importantly, TUG scores were significantly improved in week 8 before treatment compared with the values at the initial interview (Figure 5C), with a reduction of $18.3 \%$ over time.

\section{DISCUSSION}

The present pilot study sought to determine what part, if any, myofascial pain was contributing to total knee pain and immobility reported by $\mathrm{OA}$ patients. Of the 24 patients recruited to the study, all presented with active trigger points indicating myofascial pain. Of these patients with active trigger points, $92 \%$ reported a decrease in pain intensity (right now) $>20 \mathrm{~mm}$ on a $100 \mathrm{~mm}$ scale immediately after intervention. The high prevalence of myofascial pain in OA patients identified in the present study is consistent with the overall prevalence of this condition in patients with any form of chronic pain (25). Because all participants were OA patients waitlisted for TKA, our results emphasize the need for thorough pain assessment and, importantly, provide justification for a larger multicentre trial to investigate the prevalence and treatment of myofascial pain in patients with OA, with a goal of delaying or preventing TKA or improving outcome following arthroplasty surgery by decreasing pain and increasing mobility before surgery.

To our knowledge, trigger point injection in OA has been investigated in only one other study. Yentur et al (26) reported that there was a significant improvement of pain and reduction of activity restrictions observed in female patients receiving trigger point injections with lidocaine compared with only receiving an intra-articular injection of hyaluronic acid to the joint in OA patients. The study design, although not identical to the present protocol, did constitute treatment three times at one-week intervals. Similarly, improvement of knee OA pain with trigger point acupuncture was identified compared with acupuncture at standard points and sham acupuncture (27). The advancement of the present study is that knee pain in OA patients scheduled for TKA is also alleviated to a large extent with trigger

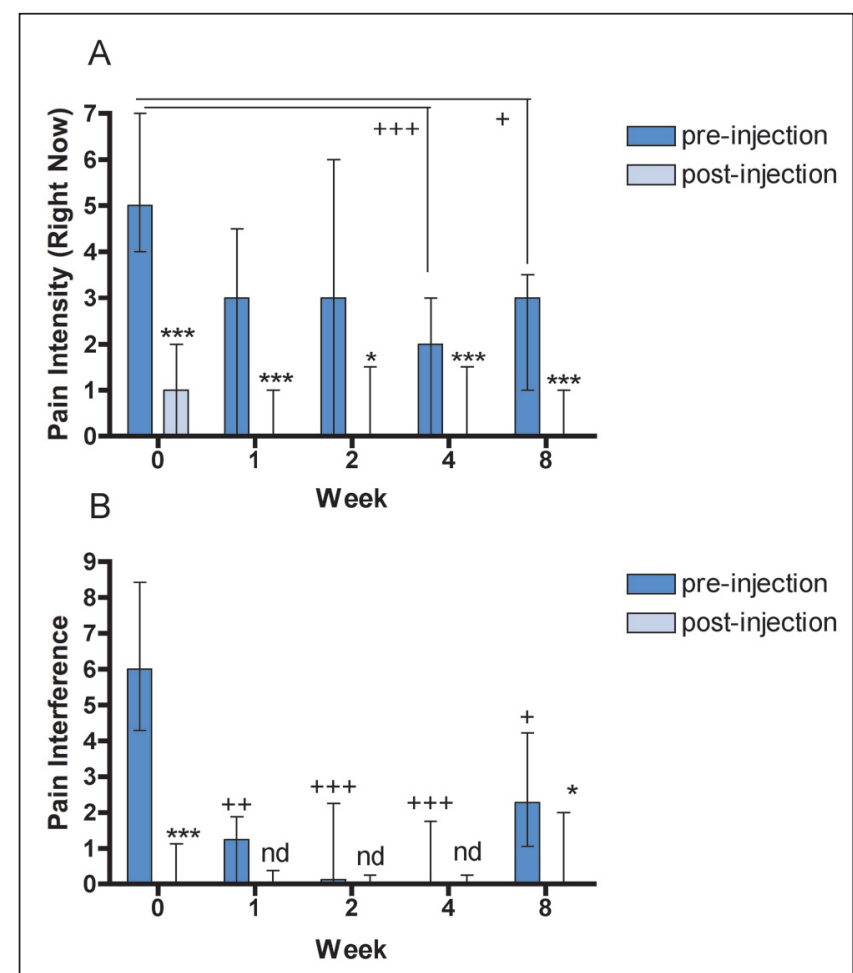

Figure 4) Outcome measures of the brief pain inventory at each time point before and following intervention (trigger point injection with bupivacaine [0.25\%]). A Pain intensity right now. B Pain interference. Data are presented as median \pm the 25 th and 75 th percentile. Statistical analysis via a nonparametric ANOVA revealed statistically significant differences from the initial time point (week 0) for each parameter: $K=20.34, P=0.0004$ for pain intensity right now; and $K=31.86, P<0.0001$ for pain interference. Post hoc analysis via Dunn's test revealed statistically significant differences for all time points compared with time point $0 ;+P<0.05,++P<0.01$, $+++P<0.001$. A Wilcoxon signed-ranked test compared before and following intervention for each time point; $* P<0.05, * * P<0.01, * * * P<0.001$. nd No significant difference

point injections and, thus, adequate management of such pain via nonsurgical interventions may be an appropriate option for these patients. 
TABLE 3

Effect of trigger point injections and secondary outcomes

\begin{tabular}{|c|c|c|c|c|c|}
\hline Outcome & Baseline & Week 1 & Week 2 & Week 4 & Week 8 \\
\hline \multicolumn{6}{|l|}{ McGill Pain Questionnaire } \\
\hline Sensory pain rating index & $11.6 \pm 6.96$ & $7.19 \pm 4.69$ & $6.55 \pm 6.13$ & $6.63 \pm 4.78$ & $5.41 \pm 5.14^{\star}$ \\
\hline Affective pain rating index & $3.12 \pm 2.92$ & $2.24 \pm 3.33$ & $1.55 \pm 2.72$ & $2.17 \pm 2.79$ & $1.76 \pm 2.79$ \\
\hline Present pain intensity \pm Visual analogue scale & $5.50 \pm 2.34$ & $3.53 \pm 2.53$ & $3.65 \pm 2.75$ & $2.70 \pm 2.01^{*}$ & $2.76 \pm 2.54^{\star}$ \\
\hline Evaluative overall intensity & $2.96 \pm 1.04$ & $2.05 \pm 1.07$ & $1.65 \pm 1.09^{* *}$ & $1.56 \pm 0.89^{\star *}$ & $1.56 \pm 1.10^{* *}$ \\
\hline \multicolumn{6}{|l|}{ Short-Form Health Survey 12} \\
\hline Physical functioning & $16.3 \pm 20.8$ & & & & $35.9 \pm 32.9^{\star}$ \\
\hline Role limitation functional & $32.6 \pm 24.3$ & & & & $52.3 \pm 31.4$ \\
\hline Pain & $34.8 \pm 22.3$ & & & & $50.0 \pm 28.3$ \\
\hline General health & $50.6 \pm 31.6$ & & & & $60.0 \pm 26.5$ \\
\hline Vitality & $35.9 \pm 27.0$ & & & & $55.0 \pm 28.7^{\star}$ \\
\hline
\end{tabular}

Data presented as mean $\pm S D$. ${ }^{*} P<0.05 ;{ }^{*} P<0.01$ compared with baseline values

Two additional observations in the present study are worthy of discussion. First, the sites of the trigger points were quite similar in most subjects and are not well represented in authoritative texts on the subject (14). Most participants had a strong trigger point in the medial head of the gastrocnemius muscle, with the vastus medialis insertion just medial to the proximal end of the patella being the second most common. Patients with lateral knee pain had involvement of the lateral gastrocnemius and vastus muscles in similar places. The muscles reported to cause knee pain are usually the quadriceps femoris (anterior) and hamstring (posterior) muscles. In the present study, we identified that the medial head of the gastrocnemius muscle (a component of the quadriceps femoris) is the principal cause of pain in patients with OA knee pain. Movement such as bending the knee or plantar flexion of the foot when walking up stairs will recruit these muscles into contraction or stretching and cause pain, which is referred and sensed in the knee joint area. Thus, it is quite easy for the patient to equate knee flexion or extension and plantar flexion with pain and assume the joint itself to be the origin of the pain. This causes the patient to report that he/she has knee pain made worse by the joint surfaces moving against one another, readily corroborated by the "bone on bone' radiological findings. Second, the response to injections followed a predictable course of muscle twitching and pain when the needle entered the trigger point, pain on infiltration of the local anesthetic into the trigger point, and rapid cessation of pain and tenderness in the minutes following the injection. The patient was then able to say where the pain had 'moved' to and the corresponding trigger point was injected, until there was little or no pain remaining. Most patients recognized the pain from the trigger point as being 'their pain' and responded euphorically to the rapid cessation of pain and resultant pain free movement.

Corroborating the results of the present study, Imamura et al (27) identified muscle pain in the same population of patients as that of the present study - patients with OA knee pain and scheduled for TKA. They reported that patients presented with trigger point pain, higher pain intensity, higher disability scores and poor quality of life compared with age-matched healthy controls, and concluded that hyperalgesia of the nervous system innervating the skeletal muscle negatively impacted pain, knee function and most aspects of quality of life. This conclusion was based on distal dermatomes presenting with lower pressure point thresholds. Indeed, there is evidence that peripheral and central sensitization contributes to OA knee pain $(4,28,29)$. Moreover, an in vivo microdialysis study of human subjects identified various pronociceptive chemicals in the trapezius muscle with active, but not latent, myofascial trigger points $(2,30)$. Central sensitization is also believed to contribute to the impairment of diffuse noxious inhibitory control in OA patients, which may account for the spread of pain to distal parts of the body $(4,31)$.

We acknowledge that there are various limitations to the present study. Most importantly, no control or sham group was included and, hence, the results may be biased toward favourable outcomes due to the lack of a measured placebo response. Control groups were purposely excluded from the present study because it was designed as a pilot to investigate the feasibility and provide proof of principle for a larger randomized study. However, sham and control groups are very difficult to incorporate because dry needling has also been found to be effective in alleviating myofascial pain $(15,16)$. An additional limitation was that the patients were not followed to assess the lasting effect of this intervention or the influence on pain following subsequent TKA. The present study was not designed to investigate the most effective treatment option to alleviate myofascial pain. Inclusion of corticosteroids into the injection and noninvasive methods such as stretching, massage, heat, ultrasound, acupuncture and physiotherapy are all interventions known to enhance and extend relief from release of the trigger points (32). Nevertheless, the results demonstrate significant decreases in pain intensity and pain interference at week $8 \mathrm{com}$ pared with baseline values obtained at week 0 . This effect outlasted the effect on any local block of pain provided by bupivacaine itself, with an expected duration of $1 \mathrm{~h}$ to $2 \mathrm{~h}$, confirming a physiological and biomechanical advantage to muscular trigger point release beyond the pharmacological effect.

$\mathrm{OA}$ is a common disease of synovial joints characterized by degenerative and reparative processes that is found in $40 \%$ of people older than 40 years of age, increasing to $90 \%$ by 80 years of age (33). However, only $50 \%$ of those with OA changes are symptomatic and the severity of radiographic changes in OA knees does not correlate well with pain or functional outcomes. Despite this understanding, radiographic presence of OA has been shown to influence the disposition of patients by the primary care physician with a higher tendency for consultation of an orthopedic surgeon. As a result, although knee pain is the primary reason a patient seeks medical help, the radiological findings ultimately have the greatest influence on the treatment offered to the patient. The outcomes of the present study clearly highlight the need for more research in this area. The increasing number of TKAs for chronic knee pain and the resultant burden this places on patients, the health care system and society in general demands attention. Improved clinical awareness of myofascial knee pain and 
early intervention/patient education may result in a reduction or delay in the number of arthroplasties performed. Further studies are required to determine whether good control of myofascial trigger points before and after surgery may reduce pain, improve mobility and range of motion, reduce hospital stays, and even reduce the number of revision surgeries undertaken. The effectiveness of trigger point injections for chronic, nonmalignant musculoskeletal pain and the considerations that should be incorporated to augment the scientific rigour of trigger point injections is provided in a recent review by Scott et al (34).

\section{REFERENCES}

1. Badley EM, Thomson RP, Wood PHN. The prevalence and severity of major disabling conditions. Int J Epidemiol 1978;7:145-51.

2. Shah JP, Phillips TM, Danoff JV, Gerber LH. An in vivo microanalytical technique for measuring the local biochemical milieu of human skeletal muscle. J Appl Physiol 2005;99:1977-84.

3. Felson DT, Naimark A, Anderson J, Kazis L, Castelli W, Meenan RF. The prevalence of knee osteoarthritis in the elderly: The Framingham Osteoarthritis Study. Arthritis Rheum 1987;30:914-8.

4. Arendt-Nielsen L, Nie H, Laursen MB, et al. Sensitization in patients with painful knee osteoarthritis. Pain 2010;149:573-81.

5. Podsiadlo D, Richardson S. The timed "Up \& Go": A test of basic functional mobility for frail elderly persons. J Am Geriatr Soc 1991;39:142-8.

6. Creamer P, Lethbridge-Cejku M, Hochberg MC. Factors associated with functional impairment in symptomatic knee osteoarthritis. Rheumatology 2000;39:490-6.

7. Salaffi F, Cavalieri F, Nolli M, Ferracciolo G. Analysis of disability in knee osteoarthritis. Relationship with age and psychological variables but not with radiographic score. J Rheumatol 1991;18:1581-6.

8. Lawrence JS, Bremner JM, Bier F. Osteo-arthrosis. Prevalence in the population and relationship between symptoms and $\mathrm{x}$-ray changes. Ann Rheum Dis 1996;25:1-24.

9. Slemenda C, Brandt KD, Heilman DK, et al. Quadriceps weakness and osteoarthritis of the knee. Ann Intern Med 1997;127:97-104.

10. Hubbard DR Jr. Chronic and recurrent muscle pain: Pathophysiology and treatment, and review of pharmacologic studies. J Musculoskelet Pain 1996;4:123-43.

11. Kirkley A, Birmingham TB, Litchfield RB, et al. A randomized trial of arthroscopic surgery for osteoarthritis of the knee. N Engl J Med 2008;359:1097-107.

12. Pendleton A, Arden N, Dougados M, et al. EULAR recommendations for the management of knee osteoarthritis: Report of a task force of the Standing Committee for International Clinical Studies Including Therapeutic Trials (ESCISIT). Ann Rheum Dis 2000;59:936-44.

13. Fishbain DA, Goldberg M, Meagher BR, Steele R, Rosomoff H. Male and female chronic pain patients categorized by DSM-III psychiatric diagnostic criteria. Pain 1986;26:181-97

14. Travell JG, Simons DG. Myofascial Pain and Dysfunction. The Trigger Point Manual. Volume 2, 2nd edn. Philadelphia: Lippincott Williams \& Wilkins, 1999.

15. Lavelle ED, Lavelle W, Smith HS. Myofascial trigger points. Anesthesiol Clinic 2007;25:841-51.

16. Yap E-C. Myofascial pain: An overview. Ann Acad Med Singapore 2007;36:43-8.

17. Dworkin RH, Turk DC, Farrar JT, et al. IMMPACT. Core outcome measures for chronic pain clinical trials: IMMPACT recommendations. Pain 2005;113:9-19.
ACKNOWLEDGEMENTS: The authors thank Rachel Phalen for careful editing of the manuscript and Shannon Zhang as the medical artist responsible for the leg muscle drawing to identify trigger point injections used in the manuscript.

FUNDING AND CONFLICTS OF INTEREST: This research was supported by the Botterell Foundation for Neurological Sciences. Dr Catherine M Cahill is supported by the Canada Research Chairs Program. The authors have no financial disclosures or conflicts of interest to declare.

18. Cleeland CS, Ryan KM. Pain assessment: Global use of the Brief Pain Inventory. Ann Acad Med Singapore 1994;23:129-38.

19. Melzack R. The short-form McGill Pain Questionnaire. Pain 1987;30:191-7.

20. Beekman ATF, Deeg DJH, van Limbeek J, et al. Criterion validity of the Center for Epidemiologic Studies Depression scale (CES-D): Results from a community based sample of older adults in the Netherlands. Psychol Med 1997;27:231-5.

21. Radloff LS. The CES-D Scale: A self-report depression scale for research in the general population. Appl Psychol Meas 1977;3:385-401.

22. Carr E, Brockbank K, Allen S, Strike P. Patterns and frequency of anxiety in women undergoing gynaecological surgery. J Clin Nursing 2006;15:341-52.

23. Oudhoff JP, Timmermans DR, Knol DL, Bijnen AB, van der Wal G. Waiting for elective general surgery: Impact on health related quality of life and psychosocial consequences. BMC Public Health 2007;7:164.

24. Farrar JT, Young JP Jr, LaMoreaux L, Werth JL, Poole RM. Clinical importance of changes in chronic pain intensity measured on an 11-point numerical pain rating scale. Pain 2001;94:149-58.

25. Gerwin RD. Neurobiology of the myofascial trigger point. Baillieres Clin Rheumatol 1994;8:747-62.

26. Yentür EA, Okçu G, Yegül I. The role of trigger point therapy in knee osteoarthritis. The Pain Clinic 2003;15:385-90.

27. Imamura M, Imamura ST, Kaziyama HH, et al. Impact of nervous system hyperalgesia on pain, disability, and quality of life in patients with knee osteoarthritis: a controlled analysis. Arthritis Rheum 2008;59:1424-31.

28. Bajaj P, Bajaj P, Graven-Nielsen T, Arendt-Nielsen L. Osteoarthritis and its association with muscle hyperalgesia: An experimental controlled study. Pain 2001;93:107-14.

29. Hoheisel U, Unger T, Mense S. Sensitization of rat dorsal horn neurons by NGF-induced subthreshold potentials and low-frequency activation. A study employing intracellular recordings in vivo. Brain Res 2007;1169:34-43.

30. Shah JP, Danoff JV, Desai MJ, et al. Biochemicals associated with pain and inflammation are elevated in sites near to and remote from active myofascial trigger points. Arch Phys Med Rehabil 2008;89:16-23.

31. Kosek E, Ordeberg G. Abnormalities of somatosensory perception in patients with painful osteoarthritis normalize following successful treatment. Eur J Pain 2000;4:229-38.

32. Han SC, Harrison P. Myofascial pain syndrome and trigger-point management. Reg Anesth 1997;22:89-101.

33. Hip and Knee Replacements in Canada. Canadian Joint Replacement Registry (CJRR) 2008-2009 Annual Report. < https://

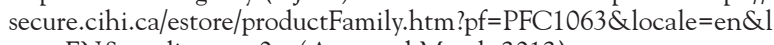
ang $=$ EN\& mediatype $=0>$ (Accessed March 2012)

34. Scott NA, Guo B, Barton PM, Gerwin RD. Trigger point injections for chronic non-malignant musculoskeletal pain: A systematic review. Pain Med 2009;10:54-69. 


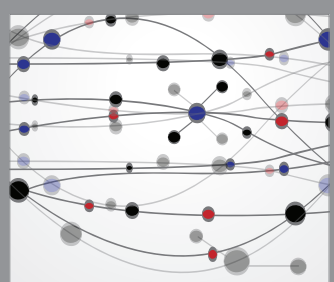

The Scientific World Journal
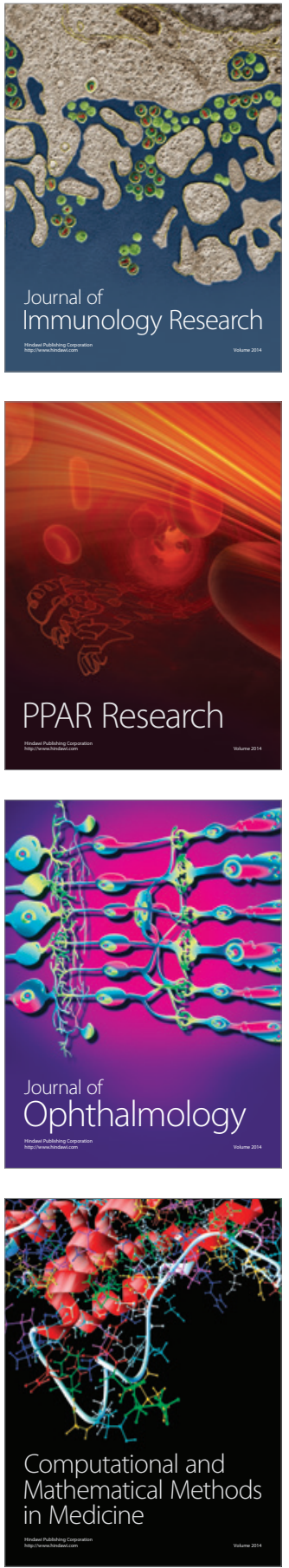

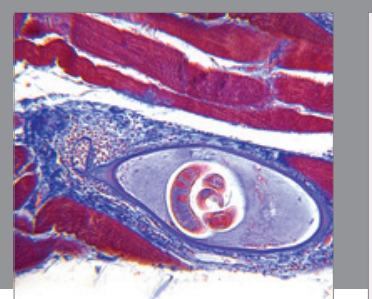

Gastroenterology Research and Practice

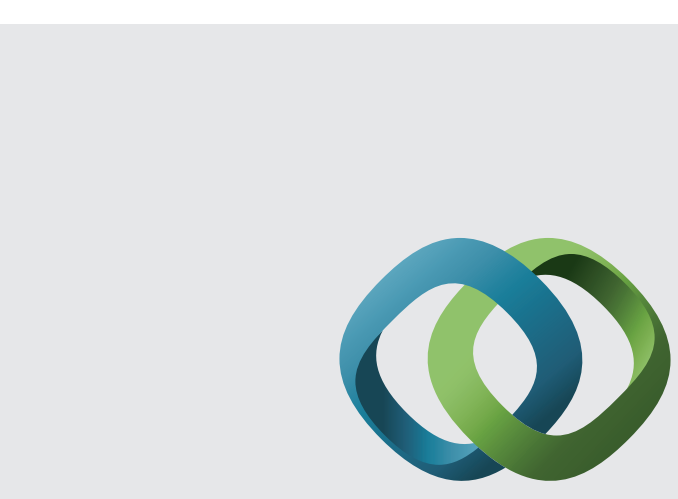

\section{Hindawi}

Submit your manuscripts at

http://www.hindawi.com
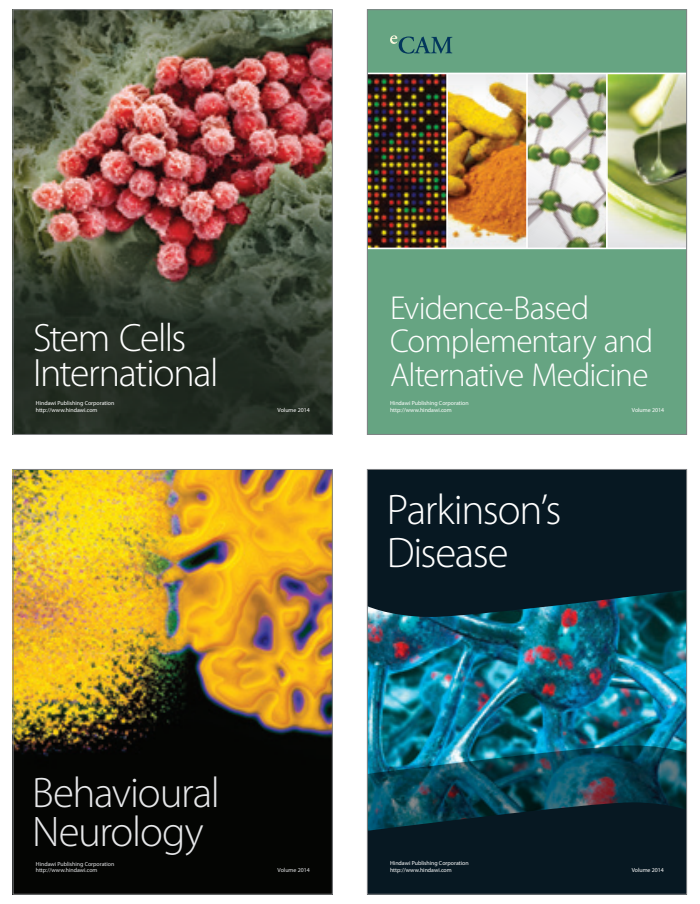
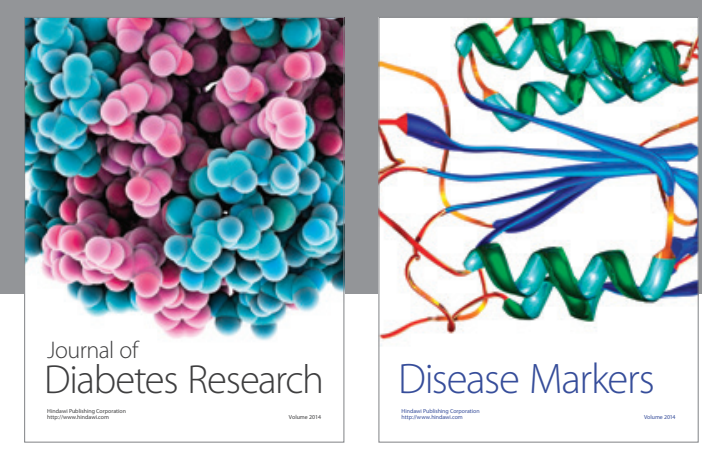

Disease Markers
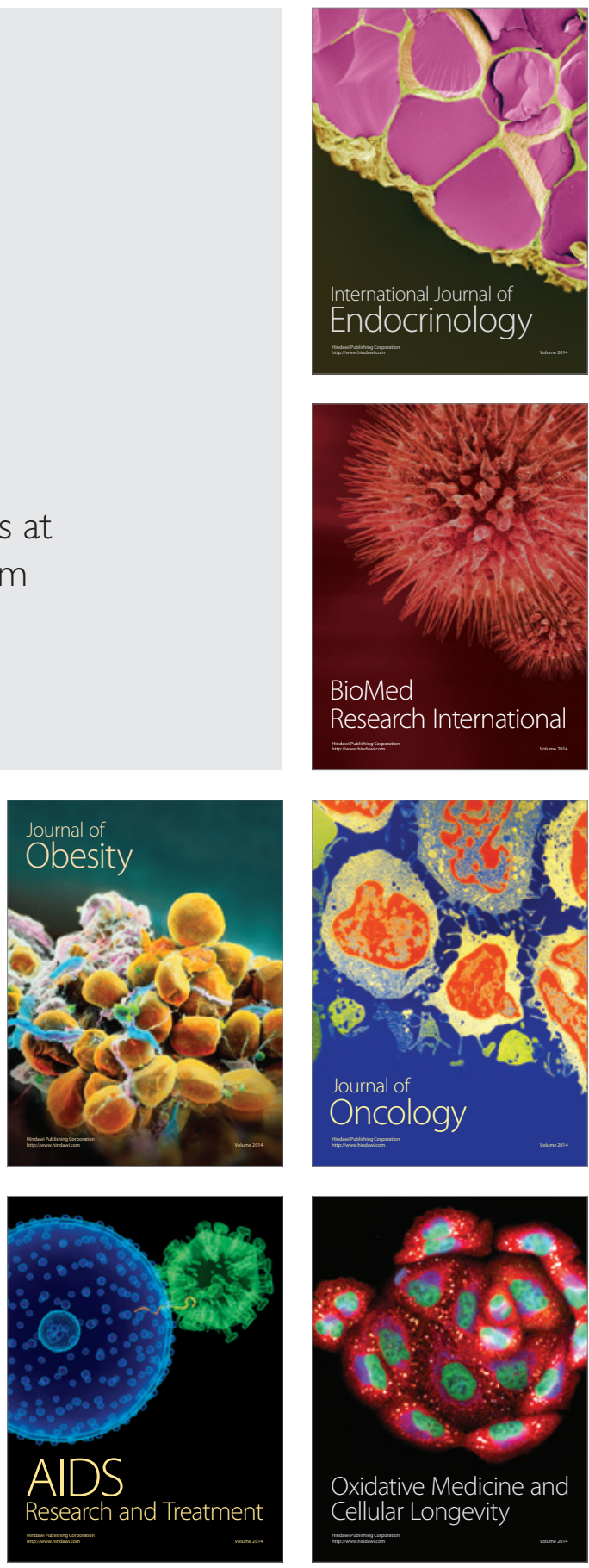